\title{
Discussion on the evaluation model of University Digital Campus Based on AHP
}

\author{
$\mathrm{Lu} \mathrm{Li}^{1, \mathrm{a}}$, Xiangui Xue $\mathrm{e}^{2, \mathrm{~b}}$ \\ ${ }^{1}$ Department of Computer and Science, Qiannan normal College for nationalities, \\ Duyun 558000,China \\ ${ }^{2}$ Department of Mathematics,Qiannan normal College for nationalities, Duyun 558000,China \\ abaoer 78@126.com, ${ }^{b}$ 877242337@qq.com
}

Keywords: University digital, AHP, Evaluation

Abstract. This research aimed at the present situation of the University digitization, using level analysis method to screen the digital evaluation factors. It established the digital campus evaluation model of colleges and universities, to expect that the application of digital campus can play its proper role.

\section{Introduction}

Digital campus is based on the network, using advanced information means and tools, to realize all digital from the environment (including equipment, classrooms, etc.), resources (such as books, notes, courseware, etc.) to the active (including teaching, learning, management, service, office, etc.). On the basis of the traditional campus, campus digitalization constructed a digital space, which purpose is to expand the space and time dimension of the campus, to improve the efficiency of the traditional campus, to extend the functionality of traditional campus, finally to realize the comprehensive information in the process of education, and to improve the quality of teaching, scientific research and the purpose of management level and efficiency.

\section{The digital construction situation of colleges and universities}

School construction of digital campus as a huge system engineering, it involves the school management, teaching, scientific research and social services, etc., its construction process is quite long process dynamic exploration practice. At the same time, each department system themselves, without unified planning, dispersion, low degree of sharing information resources, information resources waste problem, applied personnel lack the necessary training, make the application of digital campus is the key to the application effect.

\section{The digitalization construction of the establishment of the evaluation model}

To little detours in the process of digital campus construction, change ideas, to adapt to the trend of informatization, improve the quality of school teaching, scientific research and management level and efficiency, is proposed in this paper, based on the AHP evaluation model of digital campus.

AHP is a easy way for some of the more complicated and more obscure some problem to make decision.It is particularly suited to those problems is difficult to complete quantitative analysis [1]. Due to the construction of university digital campus factors and lack of quantitative data, and because of various factors, connected to each other, and mutual restriction between analytic hierarchy law can well solve these problems. It can select and sequence the various factors, and establish index factor.

Combined with field investigation and expert opinion[2,3,4,5,6,7], it was selected 14 evaluation indexes in two aspects, a total of 38 indicators.

Based on field investigation, expert scoring, and the A.L.Satty of the "1 - 9" scale method, it established the criterion layer and strategy layer judgment matrix[1].As shown in table 1. 
Table 1 Part of paired comparison matrix (the original matrix $38 * 38$ is too big, partial display)

\begin{tabular}{l|lllllllllllllll}
\hline matrix & $\mathrm{x} 1$ & $\mathrm{x} 2$ & $\mathrm{x} 3$ & $\mathrm{x} 4$ & $\mathrm{x} 5$ & $\mathrm{x} 6$ & $\mathrm{x} 7$ & $\mathrm{x} 8$ & $\mathrm{x} 9$ & $\mathrm{x} 10$ & $\mathrm{x} 11$ & $\mathrm{x} 12$ & $\mathrm{x} 13$ & $\mathrm{x} 14$ \\
\hline $\mathrm{x} 1$ & 1.0 & 1.0 & 1.0 & 4.0 & 1.0 & 1.8 & 4.0 & 0.2 & 1.0 & 4.0 & 0.2 & 4.0 & 1.0 & 1.0 \\
$\mathrm{x} 2$ & 1.0 & 1.0 & 1.0 & 4.0 & 1.0 & 1.8 & 4.0 & 0.2 & 1.0 & 4.0 & 0.2 & 4.0 & 1.0 & 1.0 \\
$\mathrm{x} 3$ & 1.0 & 1.0 & 1.0 & 4.0 & 1.0 & 1.8 & 4.0 & 0.2 & 1.0 & 4.0 & 0.2 & 4.0 & 1.0 & 1.0 \\
x4 & 0.3 & 0.3 & 0.3 & 1.0 & 0.3 & 0.4 & 1.0 & 0.0 & 0.3 & 1.0 & 0.0 & 1.0 & 0.3 & 0.3 \\
x5 & 1.0 & 1.0 & 1.0 & 4.0 & 1.0 & 1.8 & 4.0 & 0.2 & 1.0 & 4.0 & 0.2 & 4.0 & 1.0 & 1.0 \\
x6 & 0.6 & 0.6 & 0.6 & 2.3 & 0.6 & 1.0 & 2.3 & 0.1 & 0.6 & 2.3 & 0.1 & 2.3 & 0.6 & 0.6 \\
x7 & 0.3 & 0.3 & 0.3 & 1.0 & 0.3 & 0.4 & 1.0 & 0.0 & 0.3 & 1.0 & 0.0 & 1.0 & 0.3 & 0.3 \\
x8 & 6.3 & 6.3 & 6.3 & 9.0 & 6.3 & 9.0 & 9.0 & 1.0 & 6.3 & 9.0 & 1.0 & 9.0 & 6.3 & 6.3 \\
x9 & 1.0 & 1.0 & 1.0 & 4.0 & 1.0 & 1.8 & 4.0 & 0.2 & 1.0 & 4.0 & 0.2 & 4.0 & 1.0 & 1.0 \\
x10 & 0.3 & 0.3 & 0.3 & 1.0 & 0.3 & 0.4 & 1.0 & 0.0 & 0.3 & 1.0 & 0.0 & 1.0 & 0.3 & 0.3 \\
x11 & 6.3 & 6.3 & 6.3 & 9.0 & 6.3 & 9.0 & 9.0 & 1.0 & 6.3 & 9.0 & 1.0 & 9.0 & 6.3 & 6.3 \\
x12 & 0.3 & 0.3 & 0.3 & 1.0 & 0.3 & 0.4 & 1.0 & 0.0 & 0.3 & 1.0 & 0.0 & 1.0 & 0.3 & 0.3 \\
x13 & 1.0 & 1.0 & 1.0 & 4.0 & 1.0 & 1.8 & 4.0 & 0.2 & 1.0 & 4.0 & 0.2 & 4.0 & 1.0 & 1.0 \\
x14 & 1.0 & 1.0 & 1.0 & 4.0 & 1.0 & 1.8 & 4.0 & 0.2 & 1.0 & 4.0 & 0.2 & 4.0 & 1.0 & 1.0 \\
x15 & 2.3 & 2.3 & 2.3 & 9.0 & 2.3 & 4.0 & 9.0 & 0.4 & 2.3 & 9.0 & 0.4 & 9.0 & 2.3 & 2.3 \\
x16 & 1.0 & 1.0 & 1.0 & 4.0 & 1.0 & 1.8 & 4.0 & 0.2 & 1.0 & 4.0 & 0.2 & 4.0 & 1.0 & 1.0 \\
x17 & 0.3 & 0.3 & 0.3 & 1.0 & 0.3 & 0.4 & 1.0 & 0.0 & 0.3 & 1.0 & 0.0 & 1.0 & 0.3 & 0.3 \\
x18 & 2.3 & 2.3 & 2.3 & 9.0 & 2.3 & 4.0 & 9.0 & 0.4 & 2.3 & 9.0 & 0.4 & 9.0 & 2.3 & 2.3 \\
x19 & 0.3 & 0.3 & 0.3 & 1.0 & 0.3 & 0.4 & 1.0 & 0.0 & 0.3 & 1.0 & 0.0 & 1.0 & 0.3 & 0.3 \\
x20 & 1.0 & 1.0 & 1.0 & 4.0 & 1.0 & 1.8 & 4.0 & 0.2 & 1.0 & 4.0 & 0.2 & 4.0 & 1.0 & 1.0
\end{tabular}

The biggest characteristic value: 36.4438 . Assume that the corresponding eigenvectors for $\mathrm{A}$, there are:

\begin{tabular}{rrrrrrr}
{$[0.05772$} & 0.057719 & 0.057719 & 0.01443 & 0.057719 & 0.032467 & 0.01443 \\
0.30185 & 0.057719 & 0.01443 & 0.301847 & 0.01443 & 0.057719 & 0.057719 \\
0.12987 & 0.057719 & 0.01443 & 0.129868 & 0.01443 & 0.057719 & 0.057719 \\
\hline 0.01443 & 0.01443 & 0.057719 & 0.301847 & 0.301847 & 0.057719 & 0.057719 \\
0.12987 & 0.057719 & 0.301847 & 0.41702 & 0.205932 & 0.205932 & 0.057719 \\
0.30185 & 0.01443 & $0.301847]$ & & & &
\end{tabular}

The $\mathrm{Ci}=0.042059, \mathrm{CR}=0.042059 / 1.5=0.028<0.1$, in line with the consistency check, so eventually index weighting coefficient is A feature vector.

\section{Digital campus evaluation methods and examples}

In the end, to judge the degree of digital campus, it needs 38 index to make Multiple questionnaires. Each score in the table is from 1 to 10. (As shown in table 2. )The different sub indicators class table for different objects in the investigation. Combined with weight coefficient, it can be calculated the corresponding digital campus scores, and can be see digital campus degree.

Table 2 Digital level and its classification standard

\begin{tabular}{cccccc}
\hline Digital scores & $0-10$ & $10-20$ & $20-30$ & $30-39$ & $40-100$ \\
\hline Digital level & Deeply traditional & General digital & intermediate digital & high digital & outstanding digital \\
\hline
\end{tabular}

Now give a digital situation instance of western universities. The western university network facilities are complete. The university's scale is very ordinary, but each year investment fund is more, on the hardware construction of the campus. As shown in table 3.

It can be seen from table 3, the western colleges and universities network hardware facilities is fully equipped, but the digital library construction and software construction

lag behind, the final score is: $s=\sum_{i=1}^{n 2} A_{1} * C_{1}^{-} 21.5896$. Digital standard of the western campus is: moderate
digital. 
Table 3 A western campus digital investigation

\begin{tabular}{|c|c|c|}
\hline Total index layer (B) & Index $(\mathrm{X})$ & $\begin{array}{c}\text { Index score } \\
\text { (points) }\end{array}$ \\
\hline \multirow{14}{*}{$\begin{array}{l}\text { Hardware evaluation } \\
\text { index (B1) }\end{array}$} & Network infrastructure construction (X1) & 10 \\
\hline & Students have a computer rate (X2) & 3 \\
\hline & Multimedia classroom construction rate (X3) & 7 \\
\hline & Utilization frequency of multimedia classroom (X4) & 9 \\
\hline & Coverage rate of campus network (X5) & 6 \\
\hline & Campus network bandwidth (X6) & 4 \\
\hline & Wireless network coverage (X7) & 6 \\
\hline & Data query platform (X8) & 1 \\
\hline & Digital reading room (X9) & 1 \\
\hline & Digital museum (X10) & 1 \\
\hline & High performance computing, demonstration platform (X11) & 5 \\
\hline & Iot test system (X12) & 9 \\
\hline & Campus monitoring system (X13) & 10 \\
\hline & Campus rescue system $(\mathrm{X} 14)$ & 1 \\
\hline \multirow{24}{*}{$\begin{array}{l}\text { Software evaluation } \\
\text { (B2) }\end{array}$} & Network hardware and software money in years (X15) & 2 \\
\hline & Campus network docking China education and research network (X16) & 8 \\
\hline & The campus one-card system $(\mathrm{X} 17)$ & 10 \\
\hline & Network virus prevention and cure (X18) & 10 \\
\hline & Network operation failure monitoring system (X19) & 8 \\
\hline & Network technology personnel's success rate (certification) (X20) & 10 \\
\hline & Website construction of departments (X21) & 10 \\
\hline & Electronic mail system (X22) & 10 \\
\hline & Network storage space (X23) & 1 \\
\hline & The campus resource search (X24) & 1 \\
\hline & Network video interaction (X25) & 1 \\
\hline & Virtual community (X26) & 1 \\
\hline & Library digital resource download rate (X27) & 2 \\
\hline & Data interaction contribution ability (X28) & 1 \\
\hline & Network test system (X29) & 9 \\
\hline & Mobile learning system $(\mathrm{X} 30)$ & 8 \\
\hline & Scientific research exchange conversion (X31) & 3 \\
\hline & Digital leadership situation (X32) & 9 \\
\hline & The qualification rate of construction, technical support and service team (X33) & 6 \\
\hline & Digital evaluation system (X34) & 8 \\
\hline & Digital security measures (X35) & 8 \\
\hline & The digital training budgets (X36) & 8 \\
\hline & Hire personnel's information requirements (X37) & 1 \\
\hline & Informationization training proportion one year (X38) & 2 \\
\hline
\end{tabular}

\section{Conclusions}

The main purpose of building the appraisal model of digital is correct evaluation of digitized campus construction degree, and whether the digital hardware and software facilities real practical in use. If the evaluation result does not conform to the real standard of digital campus, the university can use the correct evaluation criteria perfect digital construction. Standard for digital campus of colleges and universities is to make full use of digital resources, making it truly digital. If the university is up to standard of digital campus, it is should to make full use of digital resources, making it truly digital .

This research established a scientific university digital evaluation model, using the analytic hierarchy process (ahp) and combined with MATLAB software. This research evaluated the digitization construction in view of the west campus digitalization construction of a university. The result has a certain practical reference value.

\section{Acknowledgement}

This work was financially supported by the National Natural Science Foundation of Guizhou province (LH[2015]7723), the research project of Qiannan Normal College for Nationalities ( QNSY201424 ). 


\section{References}

[1]Rui Xiong,Kunsheng Cao: submitted to Journal of Systems engineering theory and practice in Chinese (1992) .

[2]Enmin Ma: submitted to Journal of liaoning Economy vocational and technical college in Chinese (2007) .

[3]Junjuan Sun: submitted to Journal of East China Normal University in Chinese (2004).

[4]Jianwei Yan: submitted to Journal of Kunming Medical University in Chinese (2009).

[5]Guoqu Fan: submitted to Journal of Heilongjiang Science and Technology Information in Chinese (2008).

[6]Zhimin Duan,Rulong Wang,Meiqing Sun,and Wei She: submitted to Journal of Computer Engineering and Science in Chinese (2008).

[7] Dongxing Jiang,Dayong Guo,Lianlong Luo,and Qixin Liu: submitted to Journal of Xiamen University in Chinese (2007) . 